Original Research Article

\title{
Intensive care unit prophylaxis and its outcome in a rural tertiary care hospital: an observational study
}

\author{
P. Vijai Ananth ${ }^{1}$, Surendra Kumar Bouddh ${ }^{2 *}$
}

\begin{abstract}
${ }^{1}$ Department of General Medicine, ${ }^{2}$ Department of Pharmacology, Dhanalakshmi Srinivasan Medical College and Hospital, Perambalur, Tamilnadu, India
\end{abstract}

Received: 24 June 2018

Accepted: 26 July 2018

\section{*Correspondence to:}

Dr. Surendra Kumar Bouddh, Email: sk85bouddh@gmail.com

Copyright: (C) the author(s), publisher and licensee Medip Academy. This is an openaccess article distributed under the terms of the Creative Commons Attribution NonCommercial License, which permits unrestricted noncommercial use, distribution, and reproduction in any medium, provided the original work is properly cited.

\begin{abstract}
Background: Intensive Care Unit is used to treat patients closer to their beds, in order to observe them more as distinct people to almost all the critically-ill patients.

Methods: One hundred admitted patients in the ICU, 25 each sets of the patients observed their prophylactic management to prevent stress ulcer, pressure ulcer, UTI and chest infection, observations noted for the 7 days, directly by seeing and by cross-checked patient's case-sheets.

Results: There were $2(8 \%)$ patients developed stress ulcer, $1(4 \%)$ Catheter associated bacteriuria, 2 (8\%) patients grade II pressure ulcer, and $5(20 \%)$ patient's done endotracheal intubation. All these $5(20 \%)$ report of sputum culture found Ps. Aeruginosa, Klebsiella sensitive for Ceftriaxone + Sulbactum. The standard nursing care done by the on duty nursing staffs, i.e., no one given Ryle's tube feeding for the stress ulcer cases, advised soft, palatable, non-spicy oral diet, Pressure ulcer's $8 \%$ patients shifted on the air-bed mattress, ulcer's cleaned with normal water soaked soft-napkin and applied sterile pad compressed dressing locally. For the ventilator in-situ patient's, endotracheal tube cleaned 8-12 times within 12 hours. The Inbuilt Ventilator tube cleaned, and its filter changed and kept ready by the following standard aseptic precaution before using the ventilator. The chest physiotherapy was done by the chest medicine specialist of the all 5 ventilated patients. Prophylactic medication provided, i.e., Injection Pantoprazole 40mg once daily, Injection Ciprofloxacin 400mg twice daily, and Injection Inj. Ceftriaxone + Sulbactum gm 12 hourly interval administered daily. Conclusions: Standard nursing care was prime intervention as an Intensive Care Unit Prophylaxis along with Injection Pantoprazole 40mg once daily provided to prevent stress ulcer. Injection Ciprofloxacin 400mg twice daily provided to prevent Catheter Associated Bacteriuria. Injection Ceftriaxone + Sulbactum 1gm 12 hourly provided to prevent Ventilator Associate Pneumonia and pressure ulcer. Injection Ceftriaxone + Sulbactum $1 \mathrm{gm} 12$ hourly interval. Intensive Care Unit's Prophylactic measures helped to prevent further complication and reduced morbidity.
\end{abstract}

Keywords: Catheter associated bacteriuria, ICU Prophylaxis, Pressure Ulcer, Stress Ulcer, Ventilator associated pneumonia

\section{INTRODUCTION}

Many authors have written about the need to treat patients closer to their beds, in order to observe them more as distinct people. Intensive Care Unit is used to treat almost all the critically-ill patients.
There are various guidelines has been established to prevent hospital acquired chest infection, stress ulcer, Urinary tract infection, pressure ulcer to intervene in critically ill patients, the outcome were:

Stress ulcer occurs generally in the fundus and body of the stomach, but sometimes develop in the antrum, duodenum, 
or distal esophagus. The incidence of overt gastrointestinal (GI) bleeding range from 1.5 to $8.5 \%$ among all intensive care unit (ICU) patients but may be as high as 15 percent among patients who do not receive stress ulcer prophylaxis. $^{1-3}$

Almost all age groups of Indian patient's morbidity and mortality occur due to Catheter-associated urinary tract infection (CAUTI), if catheterization done. ${ }^{4}$ Nearly half of the patients who had an indwelling urinary catheter for more than 5 days done, develops Catheter Associated Bacteriuria (CAB) or candidurias. ${ }^{5,6}$ Asymptomatic bacteriuria constitutes a major pool of the antibioticresistant strains of pathogens in any hospital, with critical care units (CCUs) accounting for the majority of them. ${ }^{7,8}$

Inadequate and improper nursing care of the bed-ridden patients increase risk of Pressure ulceration, and these complications, cause the patient and their families discomfort, anguish, and economic hardship due to their expensive treatment. These pressure ulcers are a mostly avoidable incidence. ${ }^{9}$ Research has shown that when nursing staff are educated and knowledgeable on pressure ulcer prevention, nursing practice can then change and improve. ${ }^{10}$

Hospital-acquired pneumonia (HAP) is a respiratory infection develops more than $48 \mathrm{hr}$ after hospital admission. HAP affects $0.5 \%$ to $1.0 \%$ of inpatients and is the most common healthcare-associated infection (HCAI) contributing to death. ${ }^{11}$ It is estimated to increase hospital stay by 7-9 days. $^{12}$ Ventilator-associated pneumonia (VAP) accounts for up to $25 \%$ of all intensive care unit (ICU) infections with the risk being highest during early ICU stay when it is estimated to be $3 \%$ per day during the first 5 days of ventilation. ${ }^{13}$
There are various studies has been done by previous researchers. The novelty of our present study is, after generating the data, will compare the outcome with the previous already published paper through the other researchers on this area.

\section{Objectives}

- To observe prophylactic intervention for the prevention of stress ulcer, pressure ulcer Urinary tract infection and chest infection in the ICU's admitted acutely ill Critical Patients.

- $\quad$ To analyze the outcome of the prophylactic measures has been taken to prevent risk of stress ulcer, Urinary tract infection, pressure ulcer and chest infection in the ICU's admitted acutely ill Critical Patients.

\section{METHODS}

After getting ethical approval from the Institutional Ethics Committee (Human studies), and permission from the ICU in-charge to collect data, the study was initiated.

The study was Cross-sectional, single blind, Prospective study. Intensive Care Unit of the Dhanalakshmi Srinivasan Medical College and Hospital, Perambalur. All the 100 admitted patients in the ICU of a particular period of months.

\section{Parameters}

Prophylactic measures to prevent risk of stress ulcer, Urinary tract infection, pressure ulcer and ventilator associated chest infection in the ICU's admitted Patients.

Table 1: Strategies for the patient's observation.

\begin{tabular}{|llllll|}
\hline $\begin{array}{l}\text { Duration of } \\
\text { observation (days) }\end{array}$ & $\begin{array}{l}\text { Total no. of } \\
\text { patients observed }\end{array}$ & $\begin{array}{l}\text { Parameters observed } \\
\text { Stress } \\
\text { ulcer }\end{array}$ & $\begin{array}{l}\text { Urinary tract } \\
\text { infection (UTI) }\end{array}$ & $\begin{array}{l}\text { Pressure } \\
\text { ulcer }\end{array}$ & $\begin{array}{l}\text { Ventilator associated } \\
\text { Pneumonia }\end{array}$ \\
\hline 7 & 100 & 25 & 25 & 25 & 25 \\
\hline
\end{tabular}

\section{Informed Consent}

Since, it was an observational study, so to avoid bias, no need to take the consent from the observed patients and the nursing staffs as well as treating doctors on - duty in the ICU.

\section{Methods of observation}

Total 100 patient's observations noted by the Principal investigator of the study. The observations were noted directly by seeing and by cross-checked patient's casesheets.

For the each parameters 25 patient's observations noted for 7 days according to their admission in the ICU.

\section{Statistics}

The noted observational data plotted on the Microsoft Excel 2013 and calculated the number of the response and its percentage (See the details on the Results section). 
Table 2: Strategies to note observations for the stress ulcer.

Strategies for the stress ulcer

How many patients developed stress ulcer?

How many patients developed Stress ulcer induced G.I

bleeding?

How many patients given Ryle's tube feeding?

How many patients advised palatable, soft, non-spicy diet?

What prophylactic medication given to prevent stress ulcer?

Table 3: Strategies to note observations for the UTI.

Strategies for the UTI

How many patient's Urinary catheterization done?

How many patients developed Catheter Associated

Bacteriuria?

How many patients Urine culture sensitivity report done?

How many patients Urine culture sensitivity report found negative after prophylactic medication?

What prophylactic medication given to prevent Catheter Associated Bacteriuria?

Table 4: Strategies to note observations for the pressure ulcer.

\section{Strategies for the pressure ulcer}

How many patients kept on the soft-bed mattress?

How many patients developed pressure ulcer?

How many patients kept on the air-bed mattress?

How many patient's Pressure ulcers cleaned and

applied local medication and what medication?

What prophylactic medication given to prevent pressure ulcer?

\section{Table 5: Strategies to note observations for the} ventilator associated chest infection.

\begin{tabular}{l} 
Strategies for chest infection \\
How many patients kept on the Ventilator supported \\
respiration? \\
\hline $\begin{array}{l}\text { How many patient's sputum found microorganism and } \\
\text { what was its sensitivity pattern? }\end{array}$ \\
\hline How many patients Endotracheal intubation done? \\
\hline $\begin{array}{l}\text { How many patient's endotracheal tube (in-situ) } \\
\text { cleaned by the following standard aseptic precautions } \\
\text { and what was its frequency of cleaning? }\end{array}$ \\
\hline How many patient's chest physiotherapy done? \\
\hline $\begin{array}{l}\text { What prophylactic medication given to prevent } \\
\text { Ventilator associated chest infection? }\end{array}$ \\
\hline
\end{tabular}

\section{RESULTS}

The 25 patients were observed for their stress ulcer status, $2(8 \%)$ patients developed stress ulcer, and no one found GI bleeding, and no one given Ryle's tube feeding. The stress ulcer's patients were advised soft, palatable, non- spicy oral diet. Injection Pantoprazole 40mg once daily were prescribed as a prophylactic medication to the all 25 patients. The period of observation was 7 days (Figure 1).

The another 25 patients were observed for their Catheter associated bacteriuria status, $4(16 \%)$ patients inserted a closed urinary catheter drainage system, and $1(4 \%)$ developed Catheter associated bacteriuria, and Urine culture Report Found Sensitivity to Fluoroquinolone for $E$. coli. Injection Ciprofloxacin $400 \mathrm{mg}$ twice daily were prescribed as a prophylactic medication to the all 4 urinary bladder catheterized patients before doing catheterization. The $3(75 \%)$ patient's urine culture reports were found no organism after 7 days of the prophylactic medication. The period of observation was 7 days (Figure 2).

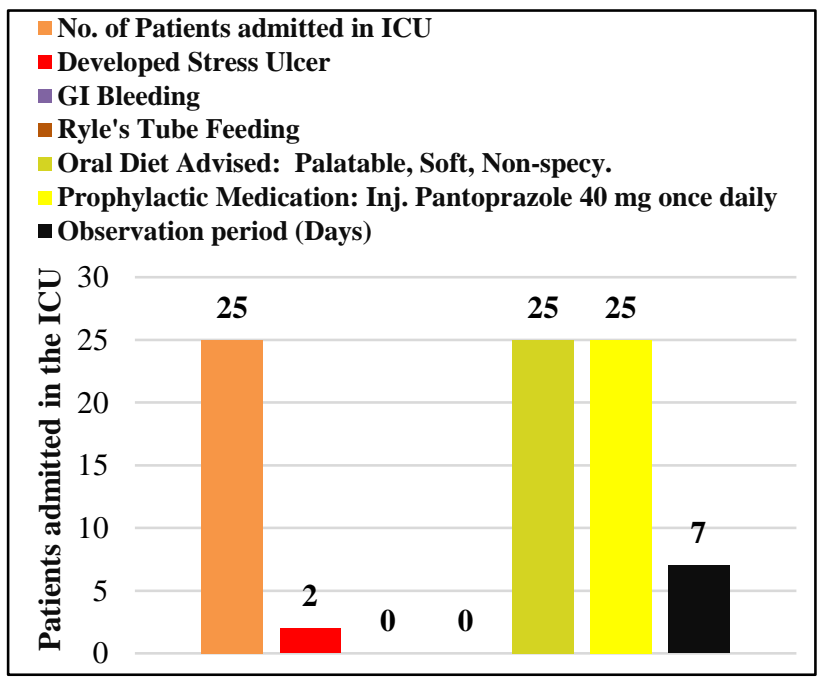

Figure 1: Observed patients in the ICU and the Prophylactic measures taken to prevent their stress ulcer.

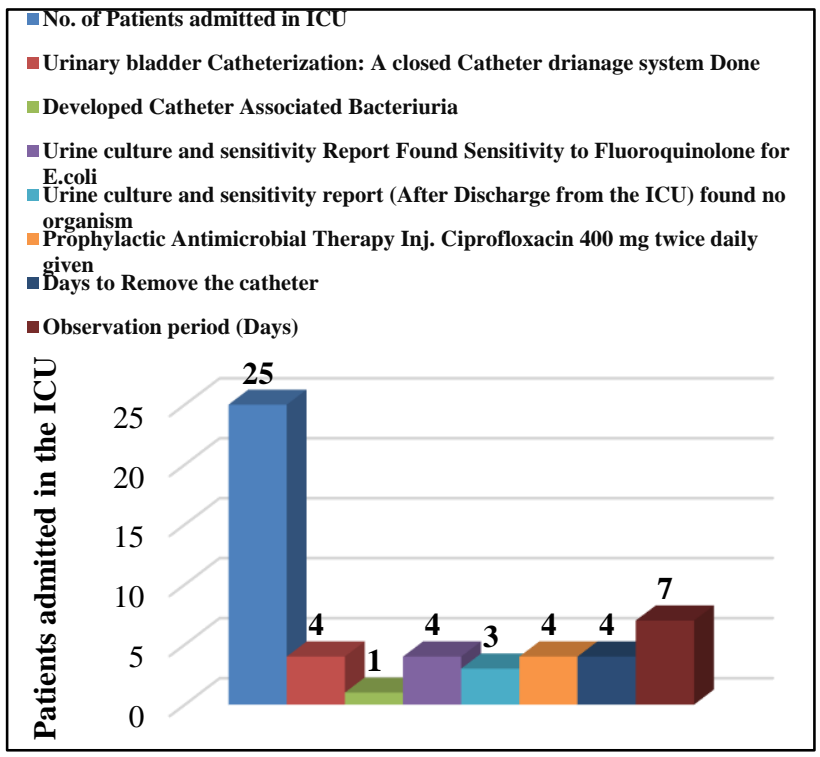

Figure 2: Observed patients in the ICU and the prophylactic measures taken to prevent their catheter associated bacteriuria. 
The another admitted 25 patients observed for their pressure ulcer, all the 25 patients kept on the soft-bed mattress, but $2(8 \%)$ patients developed grade II pressure ulcer. These $8 \%$ patients then shifted on the air-bed mattress, and pressure ulcers cleaned with normal water soaked soft-napkin and applied sterile pad compressed dressing locally daily. Injection Ceftriaxone + Sulbactum $1 \mathrm{gm} 12$ hourly interval administered daily for the 7 days as a prophylactic medication (Figure 3 ).

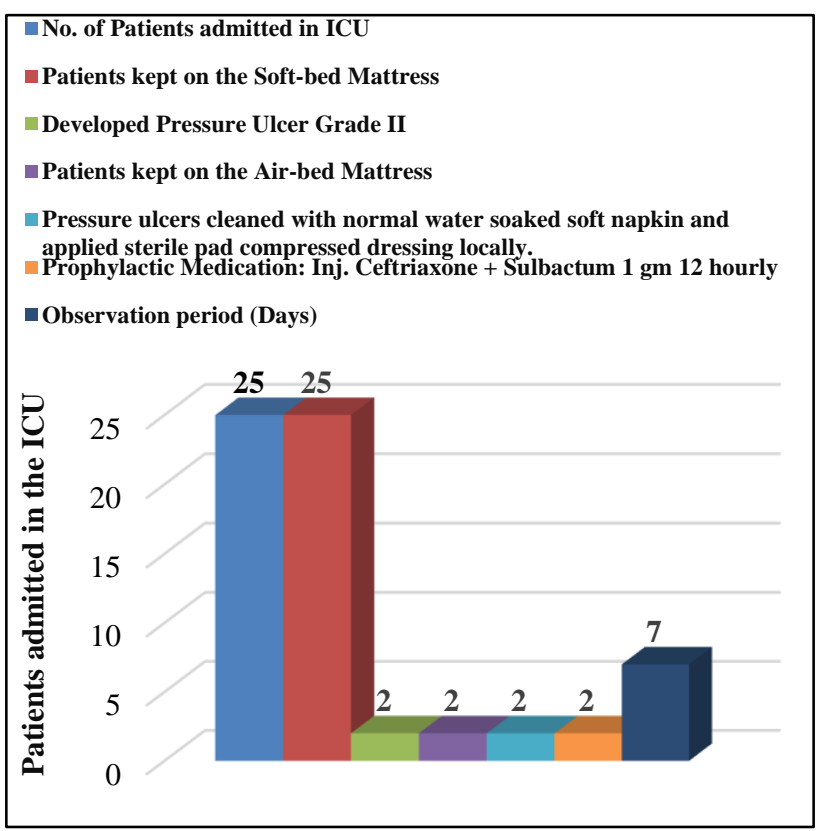

Figure 3: Observed patients in the ICU and the Prophylactic measures taken to prevent their pressure ulcer.

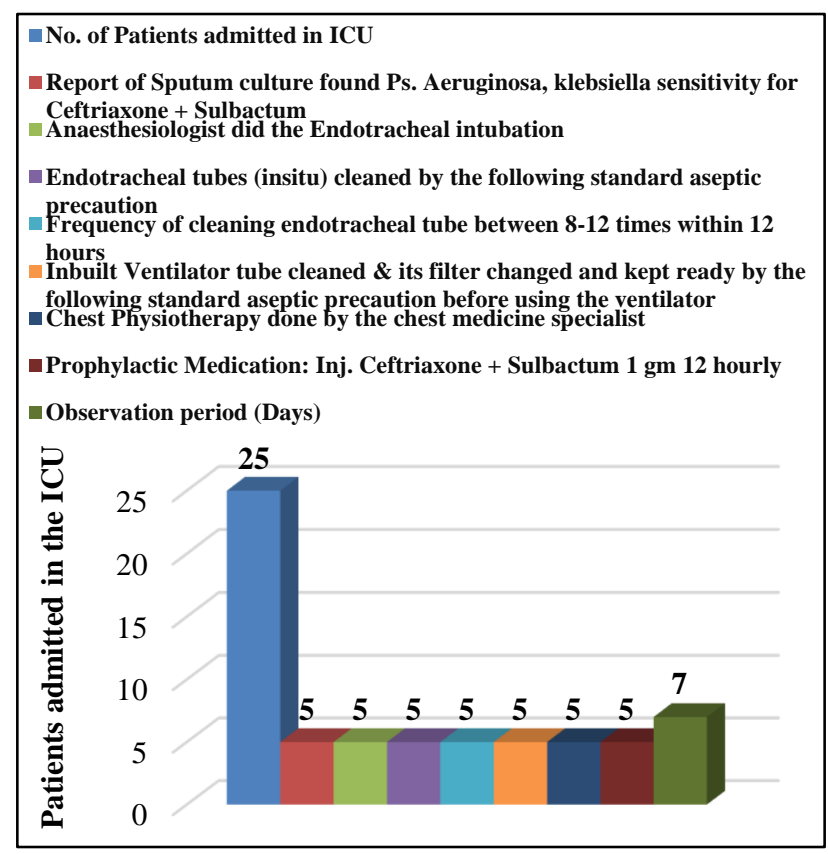

Figure 4: Observed patients in the ICU and the prophylactic measures taken to prevent their ventilator associated pneumonia.
The another sets of admitted 25 patients observed for their ventilator associated pneumonia's status. The 5 (20\%) patient's done endotracheal intubation by the anaesthesiologist. All the $5(20 \%)$ report of sputum culture found Ps. Aeruginosa, Klebsiella sensitive for Ceftriaxone + Sulbactum. The endotracheal intubation (in-situ) cleaned to the $5(20 \%)$ patients by the experienced nursing staffs by the following standard aseptic precautions. The frequency of cleaning of the 5 endotracheal intubation patients were 8-12 times within 12 hours. The Inbuilt Ventilator tube cleaned, and its filter changed and kept ready by the following standard aseptic precaution before using the ventilator. The chest physiotherapy was done by the chest medicine specialist of the all 5 ventilated patients. Injection Ceftriaxone + Sulbactum 1gm 12 hourly interval administered daily for the 7 days as a prophylactic medication (Figure 4).

\section{DISCUSSION}

Stress ulceration generally begins in the proximal regions of the stomach within hours of major trauma or serious illness. Endoscopy performed within 72 hours of a major burn or cranial trauma reveals acute mucosal abnormalities in greater than 75 percent of patients. ${ }^{14} \mathrm{Up}$ to 50 percent of such lesions have endoscopic evidence of recent or ongoing bleeding, although only a small percentage of patients experience hemodynamic compromise due to acute blood loss. ${ }^{15}$

In the present study, only $2(8 \%)$ patients developed stress ulcer on the $4^{\text {th }}$ days of ICU admission, and no one found GI bleeding. So, to prevent development of stress ulcer all the 25 patients were given Injection Pantoprazole $40 \mathrm{mg}$ once daily, advised and given soft, palatable, non-spicy oral diet, and no one given Ryle's tube feeding as a prophylactic measures. Urinary-bladder catheterization results most common health care-associated infection responsible for the development of Catheter-associated bacteriuria (CAB). ${ }^{16}$ It accounts for up to $40 \%$ of hospitalacquired infections and most of the 900,000 patients with nosocomial bacteriuria in US hospitals each year. ${ }^{17-19} \mathrm{~A}$ closed catheter drainage system and removal of the indwelling catheter within 48 hours of its insertion help to reduce the $\mathrm{CAB} .{ }^{20}$

In the present study, out of 25 ICU's admitted patients, 4 $(16 \%)$ patients inserted a closed urinary catheter drainage system, and 1 (25\%) developed Catheter associated bacteriuria, and Urine culture Report Found Sensitivity to Fluoroquinolone for $E$. coli. Injection Ciprofloxacin $400 \mathrm{mg}$ twice daily were prescribed as a prophylactic medication to the all 4 urinary bladder catheterized patients just after doing catheterization. The $3(75 \%)$ patient's urine culture reports were found no organism after 7 days of the prophylactic medication. The period of observation was 7 days.

Multiple studies show that the incidence of pressure ulcers in the ICU ranges from $10 \%$ to $41 \% .^{21-25}$ There are various 
previous study results revealed that pressure reducing devices like mattresses (alternating pressure air, low air loss and foam) are applied for $58(36.5 \%)$ patients, and most patients receive more than one nursing intervention, especially patients at pressure ulcer's risk. A study reported that, application of the Nursing interventions was skin inspection $81.8 \%$, massage with moisture cream $80.5 \%$, nutrition $68.6 \%$ and mobility $56.6 \%$ respectively. ${ }^{26}$

In the present study, authors noted observations of the 25 ICU admitted patients for their pressure ulcer, all the 25 patients kept on the soft-bed mattress, but $2(8 \%)$ patients developed grade II pressure ulcer. These $8 \%$ patients then shifted on the air-bed mattress, and pressure ulcers cleaned with normal water soaked soft-napkin and applied sterile pad compressed dressing locally daily. Injection Ceftriaxone + Sulbactum 1gm 12 hourly interval administered daily for the 7 days as a prophylactic medication.

Hospital-acquired pneumonia (HAP) is a respiratory infection develops more than $48 \mathrm{hr}$ after hospital admission. HAP affects $0.5 \%$ to $1.0 \%$ of inpatients and is the most common healthcare-associated infection (HCAI) contributing to death. ${ }^{11}$ It is estimated to increase hospital stay by 7-9 days. $^{12}$ Ventilator-associated pneumonia (VAP) accounts for up to $25 \%$ of all intensive care unit (ICU) infections with the risk being highest during early ICU stay when it is estimated to be $3 \%$ per day during the first 5 days of ventilation. ${ }^{13}$

In the present study, authors noted observations of the admitted 25 patients for their ventilator associated pneumonia's status. The $5(20 \%)$ patient's done endotracheal intubation by the anaesthesiologist. All the 5 (20\%) report of sputum culture found Ps. aeruginosa, Klebsiella sensitive for Ceftriaxone + Sulbactum. The endotracheal intubation (in-situ) cleaned to the $5(20 \%)$ patients by the experienced nursing staffs by the following standard aseptic precautions. The frequency of cleaning of the 5 endotracheal intubation patients were 8-12 times within 12 hours. The Inbuilt Ventilator tube cleaned and its filter changed and kept ready by the following standard aseptic precaution before using the ventilator. The chest physiotherapy was done by the chest medicine specialist of the all 5 ventilated patients. Injection Ceftriaxone + Sulbactum $1 \mathrm{gm} 12$ hourly interval administered daily for the 7 days as a prophylactic medication.

Since, authors considered only stress ulcer, CAB, VAP and pressure ulcer associated ICU's prophylaxis parameters. Thus, we could not concentrate on the prophylactic measures to thromboembolic episode, constipation, analgesia, sedation, Head of Bed elevation, Glucose control, etc.

\section{CONCLUSION}

Standard nursing care was prime intervention as an Intensive Care Unit Prophylaxis along with Injection
Pantoprazole $40 \mathrm{mg}$ once daily provided to prevent stress ulcer. Injection Ciprofloxacin 400mg twice daily provided to prevent Catheter Associated Bacteriuria. Injection Ceftriaxone + Sulbactum $1 \mathrm{gm} 12$ hourly provided to prevent Ventilator Associate Pneumonia and pressure ulcer. Injection Ceftriaxone + Sulbactum $1 \mathrm{gm} 12$ hourly interval. Intensive Care Unit's Prophylactic measures helped to prevent further complication and reduced morbidity.

\section{ACKNOWLEDGEMENTS}

Authors would like to acknowledge, the Head of the Department of General Medicine to given permission to initiate the study. The principal investigator would like to acknowledge hearty to the corresponding author of the study, who wrote this full manuscript, did statistical calculations and arranged the obtained observations in Bar-charts.

Funding: No funding sources

Conflict of interest: None declared

Ethical approval: The study was approved by the Institutional Ethics Committee Human Studies from the DSMCH

\section{REFERENCES}

1. Cook DJ. Stress ulcer prophylaxis: gastrointestinal bleeding and nosocomial pneumonia. Best evidence synthesis. Scand J Gastroenterol Suppl. 1995;210:48.

2. Cook DJ, Fuller HD, Guyatt GH, Marshall JC, Leasa $\mathrm{D}$, Hall R, et al. Risk factors for gastrointestinal bleeding in critically ill patients. New Eng J Medici. 1994 Feb 10;330(6):377-81.

3. Ben-Menachem T, Fogel R, Patel RV, Touchette M, Zarowitz BJ, Hadzijahic N, et al. Prophylaxis for stress-related gastric hemorrhage in the medical intensive care unit: a randomized, controlled, singleblind study. Annals of internal medicine. 1994 Oct 15;121(8):568-75.

4. Shuman RB, Schuster DP, Zuckerman GR. Prophylactic therapy for stress ulcer bleeding: a reappraisal. Ann Intern Med. 1987;106:562.

5. Cook DJ, Griffith LE, Walter SD, Guyatt GH, Meade MO, Heyland DK, et al. The attributable mortality and length of intensive care unit stay of clinically important gastrointestinal bleeding in critically ill patients. Critical care. 2001 Dec;5(6):368.

6. Tsiotos GG, Mullany CJ, Zietlow S, van Heerden JA. Abdominal complications following cardiac surgery. Am J Surg. 1994;167:553.

7. DePriest JL. Stress ulcer prophylaxis. Do critically ill patients need it? Postgrad Med. 1995;98:159.

8. Czaja AJ, McAlhany JC, Pruitt BA Jr. Acute gastroduodenal disease after thermal injury. An endoscopic evaluation of incidence and natural history. N Engl J Med. 1974;291:925.

9. Gethin G, Jordan-O'Brien J, Moore Z. Estimating costs of pressure area management based on a survey 
of ulcer care in one Irish hospital. J Wound Care. 2005; 14(4)162-5.

10. Tingle J. Pressure sores: counting the legal cost of neglect. Brit J Nurs. 1997;6(13):757.

11. Gross PA, Neu HC, Aswapokee P, Van Antwerpen C, Aswapokee N. Deaths from nosocomial infections: experience in a university hospital and a community hospital. The Amer J Med. 1980 Feb 1;68(2):219-23.

12. Leu HS, Kaiser DL, Mori M, Woolson RF, Wenzel RP. Hospital-acquired pneumonia: attributable mortality and morbidity. Ame J Epidemiol. 1989 Jun 1;129(6):1258-67.

13. Cook DJ, Walter SD, Cook RJ, Griffith LE, Guyatt $\mathrm{GH}$, Leasa D, et al. Incidence of and risk factors for ventilator-associated pneumonia in critically ill patients. Ann Intern Med. 1998 Sep 15;129(6):433-40.

14. De Priest JL. Stress ulcer prophylaxis. Do critically ill patients need it? Postgrad Med. 1995;98:159.

15. Shuman RB, Schuster DP, Zuckerman GR. Prophylactic therapy for stress ulcer bleeding: a reappraisal. Ann Intern Med. 1987;106:562.

16. Tambyah PA. Catheter-associated urinary tract infections: diagnosis and prophylaxis. Int $J$ Antimicrob Agents. 2004; 24(1):S44-S48.

17. National Nosocomial Infections Surveillance (NNIS) System Report, data summary from January 1992 through June 2004, issued October 2004. Am J Infect Control. 2004;32:470-85.

18. Haley RW, Culver DH, White JW, Morgan WM, Emori TG. The nationwide nosocomial infection rate: a new need for vital statistics. Amer J Epidemiol. 1985 Feb 1;121(2):159-67.

19. Warren JW. The catheter and urinary tract infection. Med Clin North Am. 1991;75:481-93.
20. Hooton TM. Urinary Catheter Guidelines. CID 2010:50 (1 March):627.

21. VanGilder C, Amlung S, HarrisonP, Meyer S. Results of the 2008-2009 International Pressure Ulcer Prevalence Survey and a three year acute care unit specific analysis. Ostomy Wound Manage. 2009;55(11):39-55.

22. Campbell KE, Woodbury MG, Houghton PE. Implementation of best practice in the prevention of heel pressure ulcers in the acute orthopaedic population. Int Wound J. 2010;7(1):28-40.

23. Ozedemit H, Karadag A. Prevention of pressure ulcers a descriptive study in 3 intensive care units in Turkey. J Wound Ostomy Continence Nurs. 2008;35(3):293300.

24. Nijs N, Toppets A, Defloor T, Bernarts K, Milisen K, Van Den Berghe G. Incidence and risk factors for pressure ulcers in the intensive care unit. J Clin Nurs. 2008;18:1258-66.

25. Bours GJ, DeLaat E, Halfens RJ, Lubbers $M$. Prevalence, risk factors and prevention of pressure ulcers in Dutch intensive care units. Intensive Care Med. 2001;27:1599-605.

26. Cooper KL. Evidence-Based Prevention of Pressure Ulcers in the Intensive Care Unit. Critical Care Nurse. 2013;33(6).

Cite this article as: Ananth PV, Bouddh SK. Intensive care unit prophylaxis and its outcome in a rural tertiary care hospital: an observational study. Int J Basic Clin Pharmacol 2018;7:1742-7. 